\title{
Numerical Simulation of Residual Stress and Strain Behavior After Temperature Modification
}

\author{
Farag Soul and Nada Hamdy
}

Additional information is available at the end of the chapter

http://dx.doi.org/10.5772/47745

\section{Introduction}

Welding, among all mechanical joining processes, has been employed at an increasing rate for its advantages in design flexibility. In addition to that, cost savings, reduced overall weight and enhanced structural performance. The highly localized transient heat and strongly nonlinear temperature fields in both heating and cooling processes cause non-uniform thermal expansion and contraction. Thus, result in plastic deformation in the weld and surrounding areas. As a result, residual stress, strain and distortion are permanently produced in the welded structures. This is particular when fabrication involves the use of thin section sheet materials, which are not inherently stiff enough to resist the contraction forces induced by welding. Transient thermal stresses, residual stresses, and distortion sometimes cause cracking and mismatching of joints. High tensile residual stresses are undesirable since they can contribute in causing fatigue failure, quench cracking and stress- corrosion cracking of welded structures under certain conditions. Welding deformation is undesirable owing to the decrease in buckling strength and injures the good appearance of structures.

In addition, it causes defaults during the assembly which result in repeating the process and productivity restriction. Correction of unacceptable distortion is costly and in some cases, impossible. In welding design, the study and analysis of welding residual stresses and distortion become necessary in critical industries such as: aerospace engineering, nuclear power plants, pressure vessels, boilers, marine sector....etc. Measurement of transient thermo-mechanical history during welding process is of critical importance, but proves to be prohibitively expensive and time consuming. It often fails to provide a complete picture of temperature and stress/strain, deformation distribution in the weldment. On the other hand, detailed experimental measurements of the residual elastic strain distributions in welded parts are typically not feasible due to significant resource (man, machine and material) consumption. Mathematical modeling for residual stress evaluation provides a resource 
effective method in comparison to the experimental methods when all interaction fields were correctly described in the modeling process. However, development of the modeling scheme gain demands a careful experimental data. The purpose of this chapter is to develop Finite Element models that satisfy the analysis of the behavior of transient phenomena of residual stress and distortion. That can be achieved by using different methods of the mitigation technique which work as heat transfer enhancement. Approximating the mechanisms of the transient temperature and longitudinal residual stress after temperature modification can be made. The modeled welding materials are aluminum and titanium alloys concerning flat and cylindrical shapes.

\section{The origin of residual stress}

Residual stresses developed during most manufactured processes involving metal forming, heat treatment and machining operations deform the shape or change the properties of a material. They arise from a number of sources and can be presented in the unprocessed raw materials, and can be introduced during manufacturing or can arise from in-service loading. (Withers \& Bhadeshia, 2000; Rudd, 1992; Borland, 1994; Kandil et. al. , 2001 ). The residual stresses may be high enough to cause local yielding and plastic deformation on both microscopic and macroscopic level, that can severely affect component performance. For this reason it is vital that some knowledge of the internal stress state can be deduced either from measurements or modeling predictions. Both magnitude and distribution of the residual stress can be critical to the performance that should be considered in the design of a component. Tensile residual stresses in the surface of a component are generally undesirable since they can contribute to the major cause of fatigue failure, quench cracking and stresscorrosion cracking.

Compressive residual stresses in the surface layers are usually beneficial since they increase fatigue strength, resistance to stress-corrosion cracking, and increase the bending strength of brittle ceramics and glass. In general, residual stresses are beneficial when they operate in the plane of the applied load and are opposite in sense (i.e, a compressive residual stress in a component subjected to an applied tensile load). The origins of residual stresses in a component may be classified as: mechanical, thermal and chemical. Mechanically generated residual stresses are often a result of manufacturing processes that produce non-uniform plastic deformation. They may develop naturally during processing or treatment, or may be introduced deliberately to develop a particular stress profile in a component (Brien, 2000). Examples of operations that produce undesirable surface tensile stresses or residual stress gradients are rod or wire drawing (deep deformation), welding, machining (turning, milling) and grinding (normal or harsh conditions). On a macroscopic level, thermally generated residual stresses are often the consequence of non-uniform heating or cooling operations. The residual thermal stresses coupled with the material constraints in the bulk of a large component can lead to severe thermal gradients and the development of large internal stresses. An example is the quenching of steel or aluminum alloys, which leads to surface compressive stresses, balanced by tensile stresses in the bulk of the component. 
Microscopic thermally generated residual stresses can also be developed in a material during manufacture and processing as a consequence of the CTE mismatch between different phases or constituents. The chemically generated stresses can develop due to volume changes associated with chemical reactions, precipitation, or phase transformation. Chemical surface treatments and coatings can lead to the generation of substantial residual stress gradients in the surface layers of the component. Nitriding produces compressive stress in the diffusion region because of expansion of the lattice and precipitation of nitrides also carburizing causes a similar effect (Littmann, 1964).

\section{Sheet metal fabrication}

In recent years the new vision of high-tech industrial strategy looking for minimizing the cost and increasing the strength to weight ratio of critical structure such as aerospace, marine, nuclear etc. Thin walled element fabricated by welding process can promote such effect. In the last two decades the research in welding science became more vital than other manufacturing sciences in many industrial sectors. The development in welding technology is vastly increased, and the need for sheet metal fabrication by welding is necessary for many applications. Such those applications are rockets fuel tank and aircraft exhaust and engine mounts). Typical example of some components used in industries are shown in figure 1.

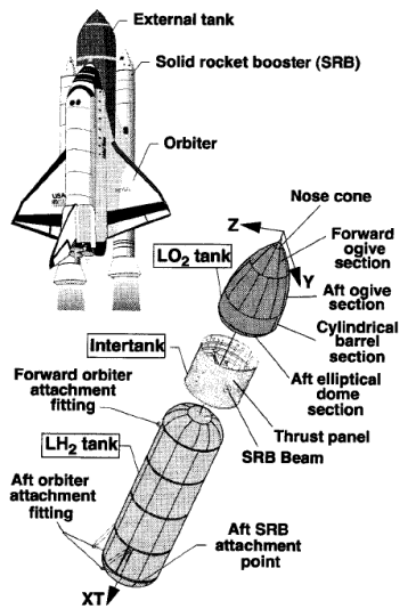

(a)

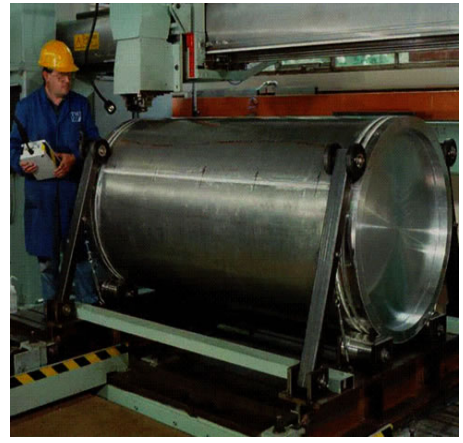

(b)

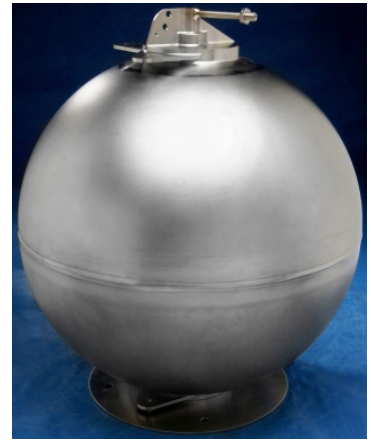

(c)

Figure 1. Typical thin welded component used in aerospace: $(a, b, c)$ type of rocket fuel tank.

Other examples of sheet metal welding applications are in ships and airplanes structures. Welding can be successfully alternated to other connection processes such as riveting. Riveting has a low joint efficiency, thus a structure designed to be riveted, generally requires more materials even if joint itself is not complex. The area adjacent to the rivets is also a site of high 
residual stresses and stresses concentration, generating a favorable environment for stress corrosion and initiation of fatigue cracks. Welding is considered a challenge for replacing riveting in the future for airbus industries. The advantage of welding compared to the mechanical fastenings, includes cost, time and ease of fabrication. Also, simpler, lighter component design, and better joint efficiency. Laser beam welding may become a new joining technique for aircraft fuselage shells for the A318 and A380 airbuses (Airbus, 2000). Laser beam welding of the longitudinal stiffeners of the skin panels of a commercial aircraft fuselage may reduce the weight of the panels to $80 \%$ against the riveted structure production Figure 2 . Welding is performed simultaneously from both sides of the stiffener. The main problem with welding is to keep the distortion as low as possible (especially the transverse deflections) and to reduce the residual stresses (especially the longitudinal tensile stresses).

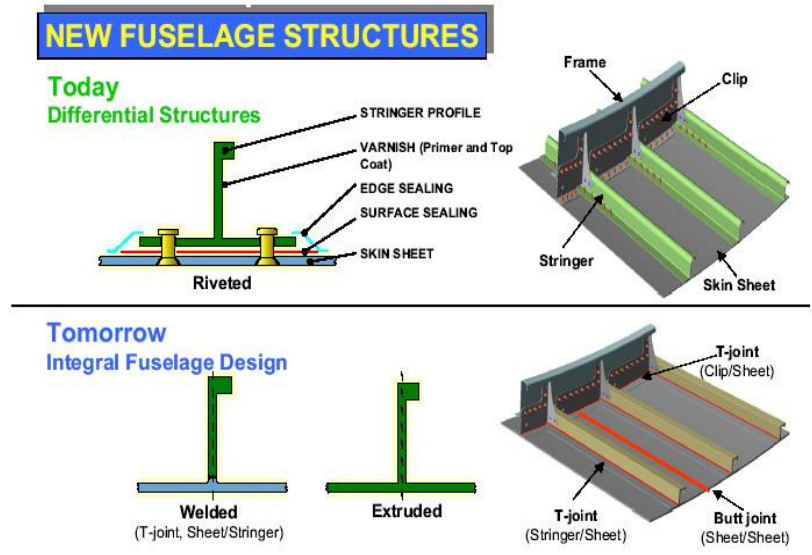

Figure 2. The fuselage structure

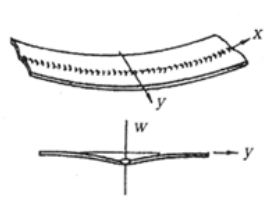

(a)

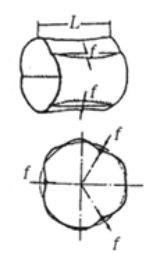

(b)
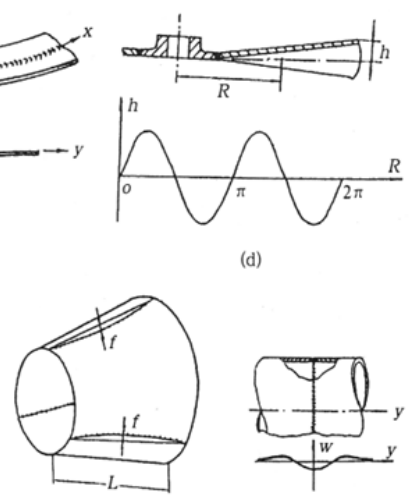

(c) (d)

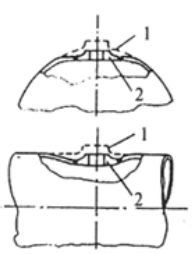

(e)

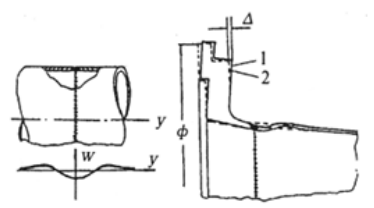

(g)

Figure 3. Typical distortion on welded sheet: longit. welds (a,b,c), circular welds $(\mathrm{d}, \mathrm{e})$, and circumference welds $(\mathrm{f}, \mathrm{g})$. 
The twin problem of stress and distortion due to welding, using conventional fusion welding process, have presented fabrication problems for many years especially, in aerospace industry. Consequently, manufacturing have applied additional time consuming and costly operations. This is to remove distortions or to relieve stresses after welding that avoid variable quality problem. This is particularly so when fabrication involves the use of thin sheet section, typically in the range of $0.5-4 \mathrm{~mm}$ in thickness. Recently advanced aluminum and titanium alloys became very attractive materials in sheet metal fabrication in high tech-industries due to their strength to weight ratio. However, as the thickness decreases, the sheet materials are not stiff enough to resist the contraction forces induced by welding. In the aerospace fabrication, the longitudinal residual stress in addition to distortion such as longitudinal bending and buckling become more substantial. The manufacturing of welded cylinders, cones or other shaped shell elements in aerospace industries are always accompanied by distortions. Figure 3, shows typical example of those distortions produced by longitudinal or circumferential welding when fusion welding process is applied (Guan, 1999).

\section{Welding and its focus research}

Historically, electric arc welding appeared in the late $19^{\text {th }}$ century, shortly after electric power became available. Other fusion welding processes were recently developed such as electron beam welding (EB) and laser beam welding (LB), which introduced new generations in the welding equipments and processes. Failure of welded bridge in Europe in the 1930 and the American liberty ships in world war II make the concern of welding mechanics is important. The welding researches carried out since that time, then vastly developed. Analyses of these subjects require complex computation; therefore, most early studies were primarily empirical or limited to the analysis of simple cases. A number of studies have been performed on the calculation of residual stress and deformation, but few are useful in the design process. Most of these calculation methods are limited for special purposes, e.g. (Hansen, 1968), or too complicated to be used in design and production, e.g. (Okerblom, 1955). (Puchaicela, 1997), exhibit some empirical formulas for general distortion modes in welded steel structures. Most of the formula are based on measurements of deformation and strains and cannot take in to account what really happens in the (HAZ) when the welding is cooling down.

Attempts were made to investigate changes in the bending deformation due varying pertinent parameters, see (Masubuchi, 1980). The investigation cover many practical aspects of process, but based mainly on experimental data. It is difficult to analyze the process, which is highly non-linear and involves plastic deformations and high temperatures varying in both time and space. Several reviews are, however, available such as the extensive review done by (Masubuchi, 1980; Radaj, 1992; Goldak et al., 1992) and the recent one by (Lindgren, 2001a, 2001b, 2001c). With the advancement of modern computers and computational techniques (for example, the finite-element and finite-difference method), a renewed effort has been made in recent years to study residual stresses and related phenomena. Therefore, it is now possible using computer programs to simulate the transient thermal stresses and metal movement during welding, as well as, the residual stresses and distortion that remain after welding is completed as found by (Tall, 1991 ; Hibbit \& Marcel, 1972; Muraki et. al., 1975; Rybicki et. al., 1978 ). 


\subsection{The finite element method in historical perspective}

The history of the finite element method is about hundred years, but it took another fifty years before the method became useful. In 1906 a paper was presented where researchers suggested a method for replacing the continuum description for stress analysis by a regular pattern of elastic bars. Later (Courant, 1943) proposed the finite element method, as we know it today, the residue of section cover the developed FEM during the years and the motivation computer tools based on FEA, and the use for those packages for simulation of welding phenomena by the researcher. Many authors have utilized the commercial finite element codes ABAQUS \& ANSYS enhanced with user subroutines, to model weld simulations with great success (Dong et. al., 1998; Feng et. al.,1996; Karlsson et. al., 1989; Grong \& Myhr, 1993; Voss et. al., 1999; Tenga \& Linb, 1998; Li et. al.,2004). The finite element code ADINAT was used by (Karlsson \& Josefson, 1990), while other authors (Junek et. al., 1999; Vincent et. al., 1999; Dubois et. al., 1984) have utilized SYSWELD to perform weld simulations. Welding is complex industrial process which often requires several trials before it can be done right. The welding is carried out by skilled workers, but in the past few years automated machines and robots are sufficiently used in the small and large industrial scales. To obtain the expected productivity through mechanization, high precision of the assembled parts must be kept. Therefore, the predictability is important in such aerospace, shipyards, nuclear and automobile industries. In order to produce a high-quality product, the accuracy control should be kept through the whole assembly line. The concept of accuracy control should be incorporated in the structural design, so that the designer can produce a better design accounting for the geometric inaccuracy. Numerical modeling and simulation of welding are a difficult and challenging problem due to the complex mechanisms involved. The wide range of problems concerned can be generalized into the fields shown in figure 4 . The fields are strongly interrelated and couple in almost every possible manner. Establishment of a model accounting for all the physical effects and their couplings would be an incomprehensibly large and complex task. Hence, welding research is characterized by choice of a focal area for thorough analysis and use of suitable assumptions. Thus, the 'art' of welding research is to choose simplifications without invalidating the research focus.

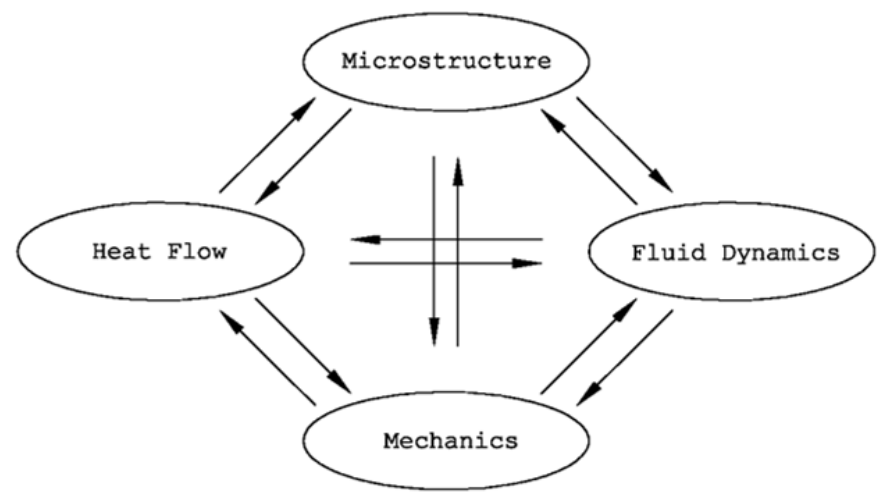

Figure 4. Coupled fields in welding analysis. 


\subsection{Welding induced residual stresses}

Stresses arising during the welding process are referred to as internal or locked-in stresses (Radaj, 1992; Gatovskii \& Karkhin, 1980). Residual stresses can be defined as those stresses that remain in a material or body after manufacture and processing in the absence of external forces or thermal gradients. Residual stress measurement techniques invariably measure strains rather than stresses, and the residual stresses are then deduced using the appropriate material parameters such as Young's modulus and Poisson's ratio. Often only a single stress value is quoted and the stresses are implicitly assumed to be constant within the measurement volume, both in the surface plane and through the depth. Residual stresses can be defined as either macro or micro stresses and both may be present in a component at anyone time. Macro residual stresses, which are often referred to as Type I residual stresses, vary within the body of the component over a range much larger than the grain size. Micro residual stresses, which result from differences within the microstructure of a material, can be classified as Type II or III. Type II residual stresses are micro residual stresses that operate at the grain-size level; Type III are generated at the atomic level. Micro residual stresses often result from the presence of different phases or constituents in a material. They can change sign or magnitude over distances comparable to the grain size of the material under analysis. To summarize, Residual stresses in the material body can be classified three type as found in (Withers \& Bhadeshia, 2000; Borland, 1994; Noyan). The different types of residual stress are shown schematically in figure 5.

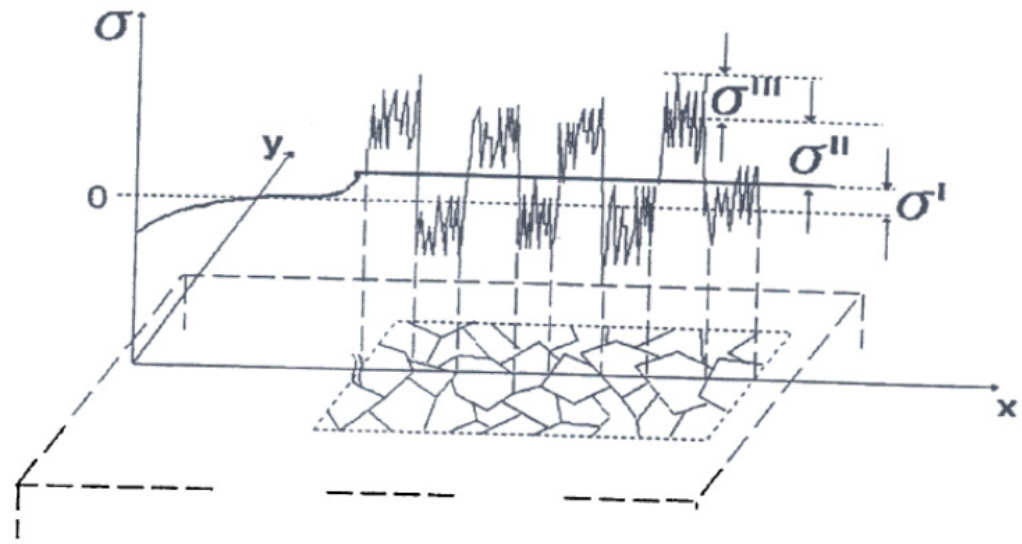

Figure 5. Categorization of residual stresses according to length scales.

Welding stresses can be classified by three characteristics: By lifetime, welding stresses can be temporary or residual, the temporary stresses do exist only in a specific moment of the non-stationary process of heating and cooling. The residual stresses can be found after the whole process of welding is completed and structure is cooled down to the room temperature. By directional the welding stresses subdivide into longitudinal (parallel to the welding direction) and transversal (perpendicular to the weld seam) and through thickness stress. By the origins, the welding stresses are subdivided into. Thermal stress, Stresses caused by the plastic deformation of the metal; Stresses caused by phase transformations. 


\subsubsection{Welding induced longitudinal residual stress}

Representation of the temperature and the resulting longitudinal stress distributions that occur during welding are schematically gives in figure 6 . In this example a simple bead-onplate case is analyzed (see figure 6a). The welding arc which is moving along the $x$-axis with a speed $v$, is indicated by the arrow. Far ahead from the heat source the temperature is constant and the stress is equal to zero in all the points. Moving in the negative direction of the $x$-axis, we reach the point where the temperature starts to rise figure $6 \mathrm{c}$. The points close to the weld line start to experience compression in the longitudinal direction. This deep fall changes to a fast rise of the longitudinal stress. The rate of stress change is proportional to the temperature gradient ahead of the source. It caused by the yielding point $\sigma$ yield changing with temperature. As known, at elevated temperatures the material begins to soften. After some temperature (the softening temperature) the material reaches the stage when $\sigma \mathrm{Y}$ is almost zero, and so, the points situated close to the centerline reach the softening temperature, and climb up to a zero value of the longitudinal stress. Stresses in the regions a short distance from the arc are compressive, because the surrounding metal restrains the expansion of these areas where the temperature is lower. However, stresses in the areas further away from the weld arc are tensile and balanced by compressive stresses in the areas near the weld. Going further, at some distance behind the welding arc, the temperature drops sufficiently for the material to be stiff enough to resist the deformation caused by the temperature change. Due to cooling the areas close to the weld contract and cause tensile stresses. After a certain time, the temperature change due to welding diminishes. High tensile longitudinal stresses (usually up to the yielding stress) are produced near the weld. In the regions further away from the weld, compressive stresses do exist. Figure $6 \mathrm{~d}$ describe the final distribution of longitudinal residual stress, from literature (Masubuchi, 1980), $\sigma x$ can be approximated by:

$$
\sigma_{x}(y)=\sigma_{m}\left[1-(y / b)^{2}\right] e^{-\left[1 / 2(y / b)^{2}\right]}
$$

Where $\sigma \mathrm{M}$ is the maximum stress at the welding line, $\mathrm{y}$ is the distance from the weld line, $\mathrm{b}$ width of tension stress.
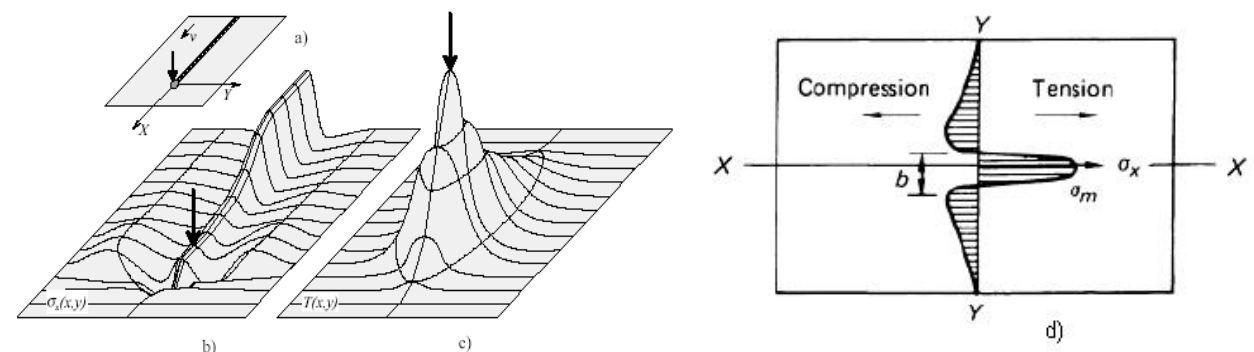

Figure 6. Schematic representation, $(a, b, c)$ temperature vs stress during welding[Pilipenko]; $d)$ final longitudinal residual stress. 


\subsection{Welding induced deformation}

As in case of the stresses occurring during and after welding, welding deformation can be transient or residual. Figure 7 gives an overview of various types of welding deformations to be expected when welding plates.

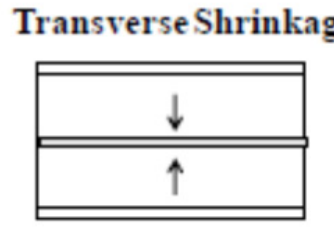

Angular Distortion

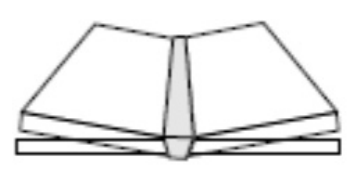

Longitudinal Shrinkage

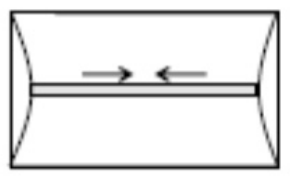

Bending

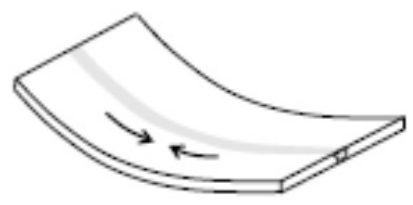

Rotational Distortion

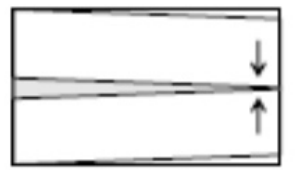

Buckling

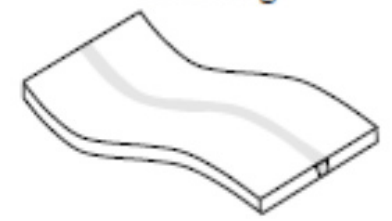

Figure 7. Different types of welding distortions. The arrows indicate the shrinkage direction of the weld metal which causes the corresponding distortion [Masubuchi 1980].

All these kinds of distortions are related to the shrinkage of the weld metal during cooling. They can be subdivided into:

1. Transverse shrinkage - shrinkage perpendicular to the weld seam

2. Longitudinal shrinkage - shrinkage in direction of the weld seam

3. Angular distortion - transverse uplift caused by a non-uniform temperature distribution in the through-thickness direction. For instance in case of butt-joints with a V-groove.

4. Rotational distortion - in-plane angular distortion due to the localized thermal expansion and contractions. Very relevant for overlap joints, for instance.

5. Bending distortion - longitudinal uplift. The same causes as angular distortion.

6. Buckling distortion - caused by compressive stresses inducing instabilities in the plates.

Driven by the need to save fuel and reduce transport and operating costs, there is a growing demand for lightweight structures, for example in the automotive and aircraft industries as well as in shipbuilding. At the very basis of this trend we find the availability of recently developed metallic alloys that actually allow the transition to more lightweight designs. Although many of the welding techniques that are currently available offer suitable material and mechanical properties, the degree of distortion remains unacceptable and residual stresses often approach component design limits. The increasing reduction in thickness will lead to a growing demand for effective solutions for residual stress and strain control during welding. An example of welding deformations in thin sheet structures can be found in the shipbuilding industry, where welding causes a typical wave-like appearance on the hull of a ship (see Figure 8). Such problem results 
through various stages of production have emerged as a major obstacle to the costeffective fabrication of lightweight structures. Same situation may occurs in aerospace and aircraft assembly where the high strength to weight ratio are necessary and thin elements are used, in addition to the requirement of smooth surface to maximize hydrodynamic performance and minimize radar signature [Huang 2004]. A conservative estimation for the labor costs accumulating for post-welding distortion correction is approximately $30 \%$ [Andersen 2000; van der Aa,2007].

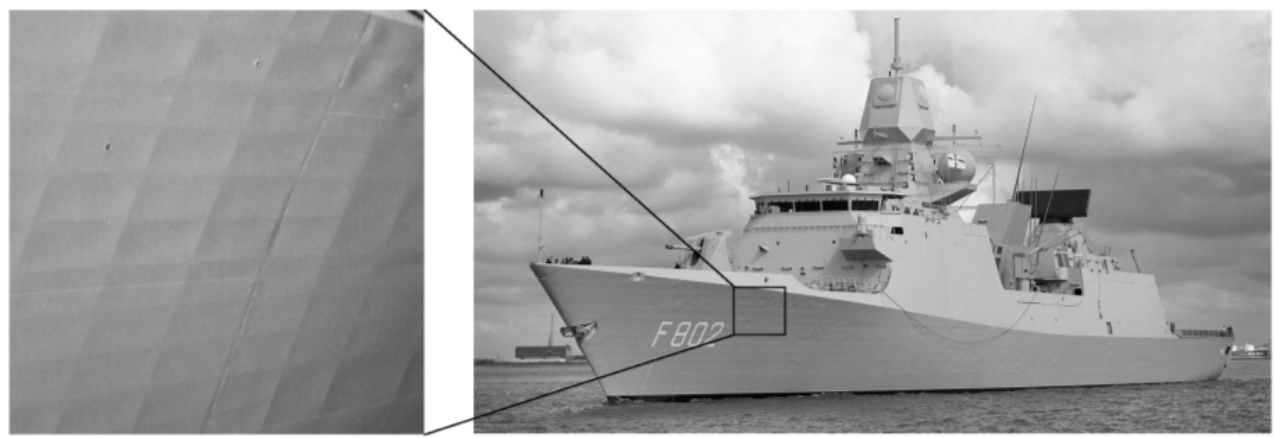

Figure 8. Ship hull defect due to distortion (van der Aa, 2007) .

\subsubsection{Bending distortion in welded sheet metal}

Bending distortion in sheet metal can be schematically shown in figure 9 . When structure is welded, heat is supplied to melt the joint and non-uniform temperature distribution is caused owing to local melting, As a result, non-uniform thermal strains and stresses are caused and plastic strains remain after thermal cycle. Residual plastic strain around welded joints is the cause of permanent deformation. Figure 9a presents the pure cambering which may occur when the ratio of sheet length to width is high enough, but when this ratio decreases, the sheet exposes both cambering and angular distortion as shown in figure $9 \mathrm{~b}$. In small thickness, angular deformation is not significant because of the high homogeneity of the temperature field through the plate thickness. In some cases gradient forces countered from longitudinal shrinkage $\mathrm{Fx}$, as shown in figure 9c, are more dominant and cause the cambering owing to low stiffness of thin sheet at this moment. This may occur when the longitudinal residual stress above the neutral axis of the sheet exceeds that below the neutral axis.

The possibility for minimizing or eliminating this problem is only to balance the longitudinal stress around the neutral axis otherwise, minimizing these stresses below the significant magnitude which not exceeds the component stiffness. For most welding processes, the incident surface will absorb the most energy, with the energy absorption decreasing with depth. The variation in the through-thickness heating causes variation in the longitudinal stresses through the plate thickness. This generates a bending moment, which causes the bending distortion mode. 
(a)

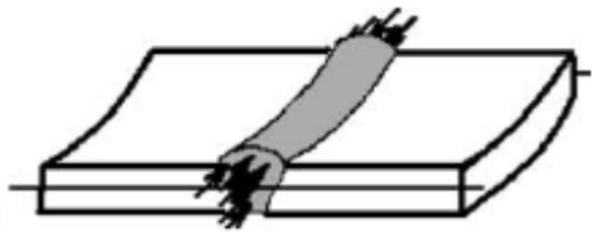

(b)

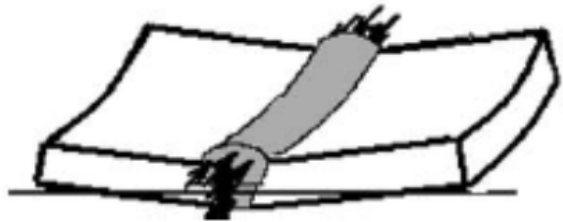

(c)

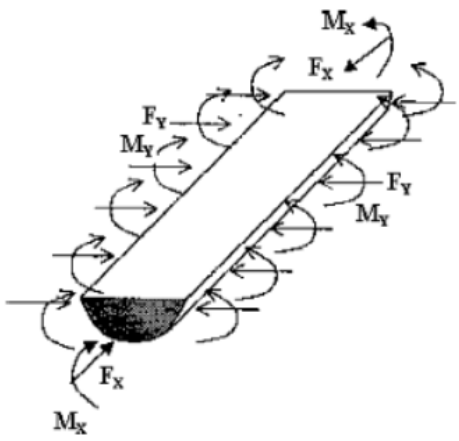

Figure 9. Schematic of: (a) cambering; (b) combined cambering and angular; (c) Shrinkage foresees in inherent strain region.

\subsection{Novel control techniques for residual stress and distortion}

Controlling of distortion has been investigated in series of papers by the Edison welding institute (EWI) (Conrady \& Dull, 1995; Michaleris et al., 1999; Michaleris \& Sun, 1997; Conrardy \& Dull, 1997). Those papers concerned for the thermal tensioning technique in both static and dynamic heating during welding processes. The technique was found to be an active method in welded ship structures. Different heating sources can be used enhancing tensioning effect such as dynamic flame heating and moving laser spot heating or static heating. Another mitigation technique for controlling welding-induced stresses and distortion has been developed by Beijing Aeronautical Manufacturing Technology Research institute (Q. Guan et. al., 1994; Guan et al., 1993). The technique called dynamic controlled low stress no distortion (DC-LSND); it has been applied successfully to aerospace manufacturing for shell structures such as jet engine cases of heat resistance alloys and rocket fuel tanks of aluminum alloys (Guan et al., 1993; Guan et al., 1996). Many literature present that the residual stress can be minimized by using (DC-LSND) welding technique ( Li et al , 2004a; Li et al., 2004b). many cooling media can be used in this technique such as (atomized water, compressed air, solid $\mathrm{CO}_{2}$, liquid nitrogen, liquid argon). Beside the reduction of plastic strain, it was found that heat transfer enhancement by trailing heat sink technique work as source for balancing residual stresses above and under the neutral axis (Soul \& Yanhua, 2005, 2006; Soul et al, 2010). The set-up of dynamic heating spots and trailing heat sink are represented schematically in figure 10. The studies on the temperature field characteristics and the thermal history are the foundation and prerequisite to study the stress and distortion control mechanism in welding mitigating techniques. Sometimes, it is inconvenient or even impossible to obtain the real thermal cycle at weld pool by experiment due to its limitations. 


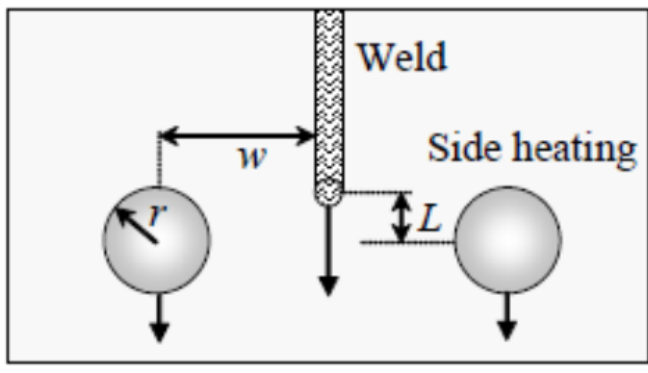

(a)

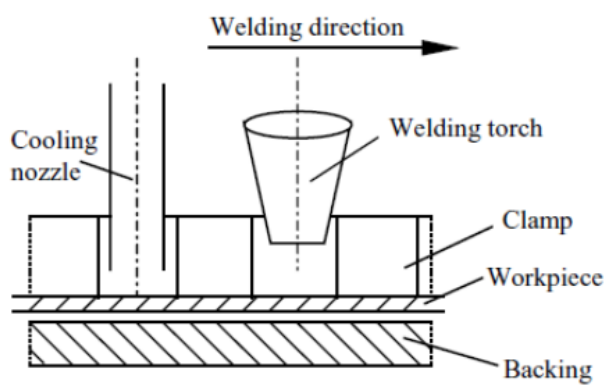

(b)

Figure 10. Schematic drawing represents: (a) moving heating spots; (b) trailing cooling spot

To overcome this disadvantage, the advanced numerical analysis technologies, such as finite element method and finite difference method, have been frequently used to obtain the whole temperature field of the welded specimen. It is necessary to develop a computer-based tool to optimize welding mitigation processes and hence minimize the expense and time incurred by extensive welding trials. In this chapter three dimensional finite element methods are employed to find qualitative analysis for the temperature field, residual stress and transient plastic strain developed during welding process. To mitigate the problem of residual stress and distortion, two different techniques were tested and compared, those are trailing heat sink and dynamic heating spots techniques. Gas tungsten arc welding process (GTAW) is used for simulation.

\section{Investigation of residual stress behaviour after enhanced heat transfer}

\subsection{Trailing cooling spot}

The proposed welding technique incorporates a trailing heat sink (an intense cooling source) with respect to the welding torch, and it is also named Low Stress No Distortion (LSND) welding. The development of this mitigation technique is based on both detailed welding process simulation using advanced finite element method and systematic laboratory trials. For understanding well LSND welding, finite element method is used to investigate the mechanism of the technique. In this chapter, 3D-FEA results from different papers done by the author have been selected. These results study the mechanism of the trailing heat sink mitigation technique and how the longitudinal residual stress was minimized based on the distance between the torch and the cooling spot. The qualitative and quantitative analysis of residual stress depend on the temperature gradient in the component during heating and cooling. So any modification of temperature topography may decrease or increase the residual stress that depends on interaction of strains. Three-dimensional models for welding, the thermal cycle and residual stress in welding are now in common use as a research tool for both academic and commercial purposes. The models use a transient 3dimensional thermal model which is decoupled to an elastic-plastic model for calculating the stress and strain. Models were investigated with different material and dimension as shown in table 1. 


\begin{tabular}{|l|c|c|}
\hline Model & Size & geometry \\
\hline Model 1 Al-Mn(3003) & $260 \mathrm{~mm} \times 130 \mathrm{~mm} \times 2 \mathrm{~mm}$ & Flat sheet \\
\hline Model 2 Al-Mg (5083) & $240 \mathrm{~mm} \times 80 \mathrm{~mm} \times 3 \mathrm{~mm}$ & Flat sheet \\
\hline Model 3 Ti-6Al-4V & $270 \mathrm{~mm} \times 120 \mathrm{~mm} \times 2.5 \mathrm{~mm}$ & Flat sheet \\
\hline Model4 AL-Cu (2024 & $100 \mathrm{mmOD}, 96 \mathrm{mmID}, 240 \mathrm{~mm}$ length & Cylindrical sheet \\
\hline
\end{tabular}

Table 1. Simulated models: material, shapes and their dimensions.

\subsubsection{Establishment of heat source model}

In this study, two heat source models were investigated, then correlated on fitting a practical welded sample for distinguishing the better one, so it can be used to detect other analysis. The first one is disc model proposed by (pavelic et al, 1969 ), the mathematical expression of the model present in Equation 2.

$$
q(r)=\frac{3 Q}{\pi r_{0}{ }^{2}} e^{-\frac{3}{r_{0}^{2}} r^{2}}
$$

Where $\mathrm{q}(\mathrm{r})$ is the surface flux at radius $r\left(\mathrm{~W} / \mathrm{m}^{2}\right), \mathrm{r} 0$ is the region in which $95 \%$ of the heat flux is deposited, $\mathrm{r}$ is radial distance from center of the heat source and $\mathrm{Q}$ is the heat input.

The second model is double ellipsoidal power density distribution" adopted from (Goldak, 1984), the mathematical expression of the model present in Equations 3 and 4.

$$
\begin{aligned}
& q_{f}(x, y, z)=\frac{6 \sqrt{3} Q f_{f}}{a b c_{f} \pi \sqrt{\pi}} e^{\left(-3 x^{2} / a^{2}\right)} e^{\left(-3 y^{2} / b^{2}\right)} e^{\left(-3 z^{2} / c_{f}^{2}\right)} \\
& q_{r}(x, y, z)=\frac{6 \sqrt{3} Q f_{r}}{a b c_{r} \pi \sqrt{\pi}} e^{\left(-3 x^{2} / a^{2}\right)} e^{\left(-3 y^{2} / b^{2}\right)} e^{\left(-3 z^{2} / c_{r}^{2}\right)}
\end{aligned}
$$

Where $a, b, c$ are the semi-axis for the gaussian distribution in $(x, y, z)$ direction respectively and $f_{f}, f_{r}$ are fractions of heat deposit in front and rear of the heat source. The intensity plot for both surface heat and double ellipsoid heat source models is shown in figure 11. Variation of the semi-axis and the heat deposit fractions allows the double ellipsoid fitted to give suitable heat source especially at increased welding speed.

At the same heat input, the double ellipsoid is more reasonable for fitting the fusion boundary rather than the gaussian distribution or surface heat source model as depicted in figure 12 . 


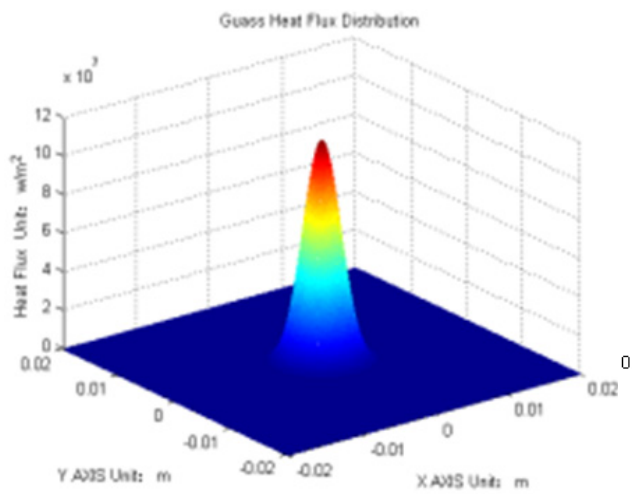

(a)

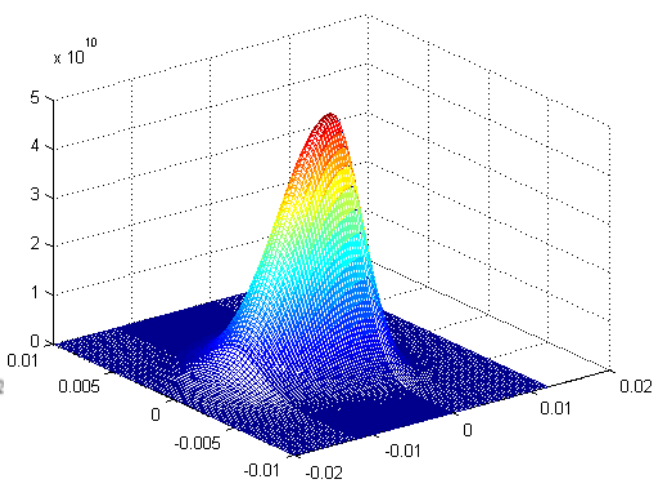

(b)

Figure 11. Intensity of heat source model: (a) gaussian distribution; b) double ellipsoid

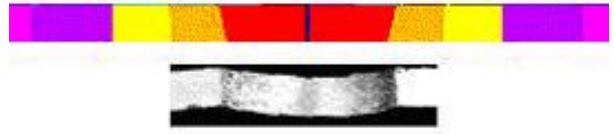

(a)

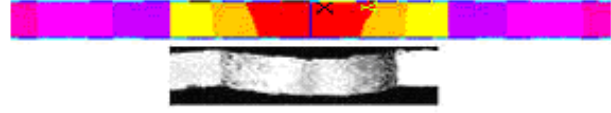

(b)

Figure 12. Experimental \& simulated fusion boundary fitting: (a) double ellipsoid; (b) gaussian distribution;

\subsubsection{Effects of trailing cooling spot on heat transfer form}

The temperature distribution resulted from the thermal analysis for the heat sink process stated above is predicted at a welding time of $25 \mathrm{~s}$ and presented in Figure 13. The temperature decreases drastically in the zone between the arc and the heat sink, and the corresponding temperature gradient increases. Further more, in the front of the heat sink the temperature isotherms reveals the existence of high temperature gradient and therefore, some of high temperature contours are drawn back to the front of heat sink and distorted temperature distribution were formed. However, the point in and near the weld centerline may passed by more than one thermal cycle and this may expressed as [heating - normal cooling - forced cooling - surrounding heating - normal cooling]. The evidence of those cycles became more clear when different locations in the samples in both conventional and after applying heat sink processes were selected. Figure 14 reveals different location with difference cycle profiles.

The locations at or near the weld line present those cycles and exhibit significance difference in thermal profiles. The point at weld line reveals the maximum intensity of the cooling spot which indicate a steep profile and the existence of valley. The thickness of the modeled sample play an important role for the effectiveness of the technique. Figure 14c shows the thermal history of simulated welded aluminum alloy with $2 \mathrm{~mm}$ in thickness 


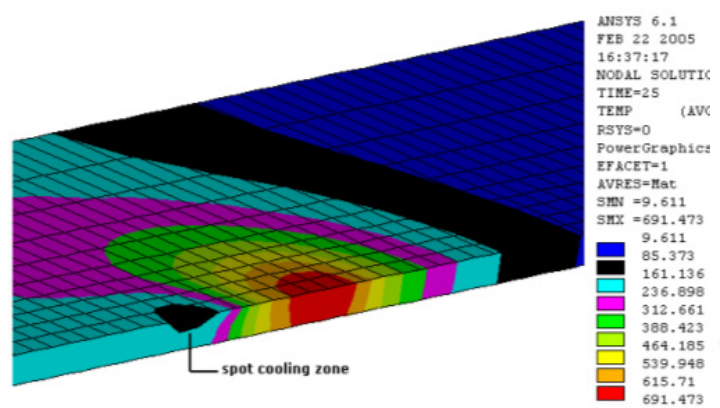

(a)

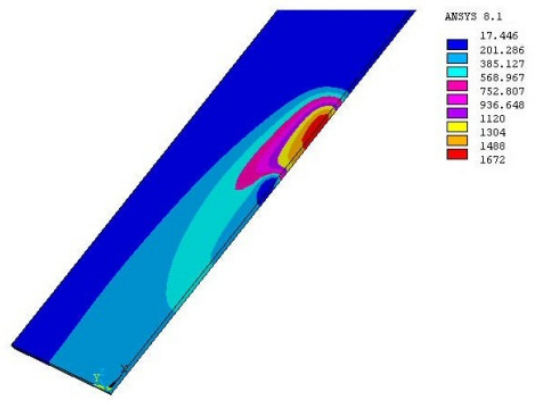

(b)

Figure 13. Temperature contours in trailing cooling spot: a) Al-alloy; b) Ti- alloy (soul, 2oo5,2006)

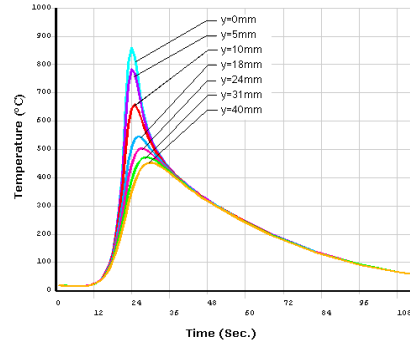

(a)

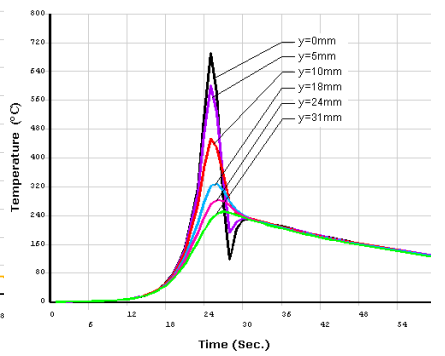

(b)

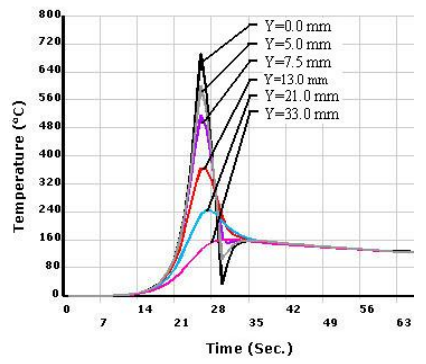

(c)

Figure 14. Thermal history: (a) conventional welding; (b) trailing cooling spot $[\mathrm{t}=3 \mathrm{~mm}]$, (c) [t=2mm]

Comparing these results with that modeled with thickness $3 \mathrm{~mm}$ as presented in figure $14 \mathrm{~b}$, at the point $(y=0)$, the penetration of cooling zone is more effective in the small thickness, which reveals lower temperature magnitude at the center of the spot figure 14c. Moreover, 
the overall temperature tips in thermal history is decreased compared with conventional welding. This refers to some energy absorbed from the total energy by the amount action of introduced cooling.

\subsubsection{Longitudinal residual stress behaviour}

The result obtained from the 3-D modeling of welding a bead on plate with thickness $2.5 \mathrm{~mm}$ for titanium alloy and $3 \mathrm{~mm}$ for aluminum alloy using GTAW process were depicted in figure 15. Describing the process behavior, in the front of the torch, compression transient residual stress were developed which result from generated thermal strain. When the material loose the mechanical properties at high temperature such yield strength and young's modulus, no extra stresses were produced. Behind the welding pool when the shrinkage started, plastic strain was accumulated and transient residual stress changes from compression to tension in short period of time. Therefore, Its magnitude increased vastly as the temperature decreased. However, it is an important knowledge if this change with duration can be measured practically to make correlation, but it is so difficult. In fact, the final magnitude of residual stress depends on cooling rate, regarding the metallurgical science welding microstructure morphology and size depend on the cooling rate as well. So no welding residual stress developed if there is no change or homogenous microstructure was obtained.

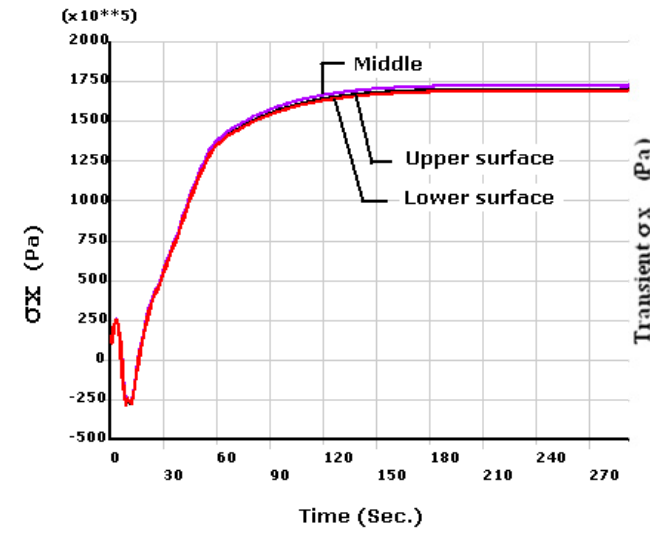

(a)

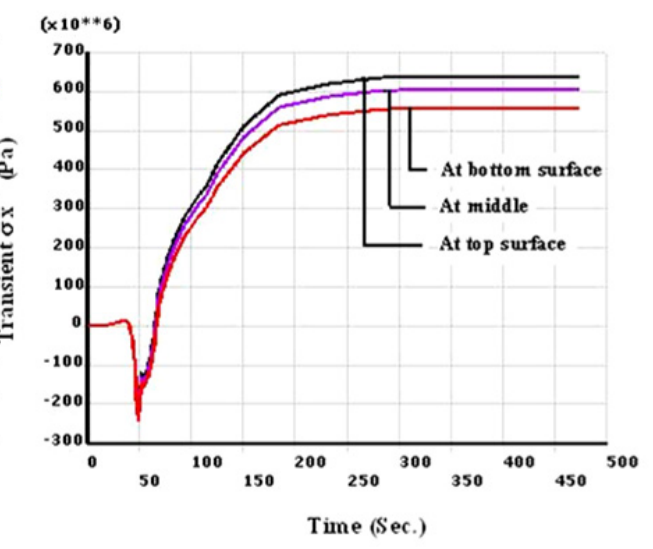

(b)

Figure 15. Transient residual stress: (a) Al-Mg alloy; (b) Ti-6Al-4V alloy

In more details, after including trailing heat sink technique, which can enhance heat transfer process, the temperature was modified. The analyzed results in figure 16 obtained when the trailing heat sink is located at $30 \mathrm{~mm}$ behind the torch, exhibit that the stress profile has different behavior. For instance, in small area depicted in figure 16a (zone of compressed contours), the contours behind the torch were compressed in the front of the cooling spot, and its shape becomes in complicated form through this stage. 


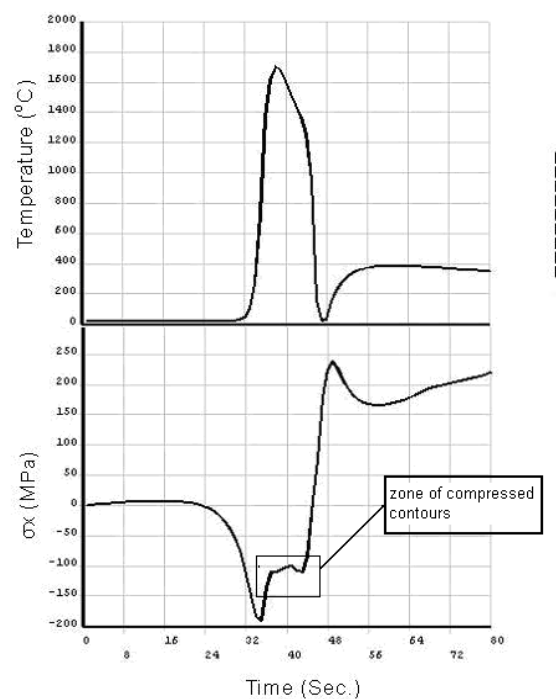

(a)

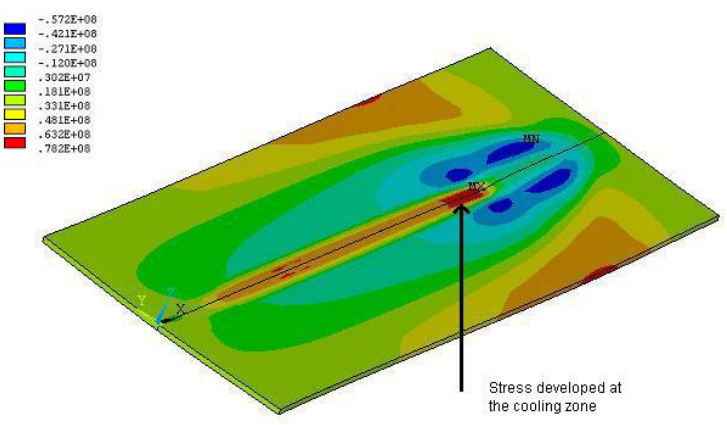

(b)

Figure 16. Transient longitudinal residual: (a) stress vs thermal cycle ; (b) longitudinal residual stress contours Al-Mn alloy

The transient longitudinal residual stress stays constant for a period of time, this may also be referred to the high temperature contours intercepted between the two sources which don't affect the plastic strain. Through enough length along weld centerline behind cooling zone, the longitudinal residual stress seams to have a constant value which can be distinguished from a stable color along this length. This behavior coupled with the constant values of contours around mentioned length.

Moving a step back, far from local cooling zone, the temperature of the metal at the spotcooling region is smaller than the surrounding, so the fast contraction of welded metal in the cooling zone and high transient longitudinal residual stress may developed as depicted in figure 16b (red color were the arrow located). Because of cooling that crossed in a short time and the hot contours appeared again due to the hot surrounding material, the residual plastic strain may released and recovery process may generate. However, both the effectiveness of the cooling at the upper surface and the abnormal temperature developed behind the heat source may affect the balance level for the front-to-rear stress pattern. Furthermore, in short distance behind the torch, high temperature contours around the cooling zone and low temperature inside, which revealed a big difference from that occurred in conventional welding process. Therefore, it may brought less stress during solidification temperature range, and reasonable longitudinal strain can be obtained. Behind the cooling zone the transient longitudinal residual stress profile seems to be decreases to somewhat value due to an increase in temperature as shown in figure 17. In this stage, the process became as heat treatment for the residual stress, and the metal may expand again due to heating which believed to be appeared in the expansion process in the rear of the cooling zone. 
The drop in residual stress magnitude follows the change in temperature according to the thermal cycle may refer to the opposite change of the elastic strain when the temperature increases again by the surrounding hot metal. Therefore, the reasonable expression for this mechanism related to recovery process due to the heating process behind the cooling spot which may expand again, and then some of the plastic strain can be released. In practice, this process is quite logic during the heat treatment of materials suffering from residual stress induced by welding or other strengthening process such as cold working etc. Furthermore, the maximum longitudinal residual stress in titanium model is reduced to about ( $326 \mathrm{MPa})$ from that in conventional welding, where in the aluminum model the maximum residual stress is minimized about ( $55 \mathrm{MPa})$ from that in conventional welding. The tested technique shows the significance influence on the final longitudinal residual stress through thickness, the clear evidence for such influence can be seen in figure 18 . The residual stress at the upper surface became less in magnitude than that in the middle of plate thickness. It seems not only the over all stress minimization but the possibilities for balance the stresses around the center of the Thickness.

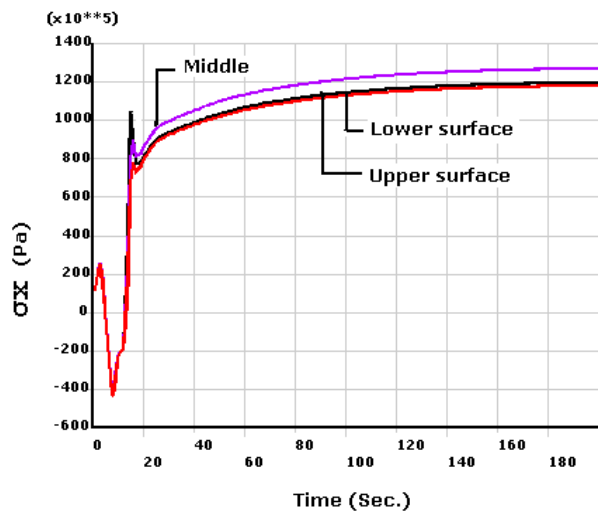

(a)

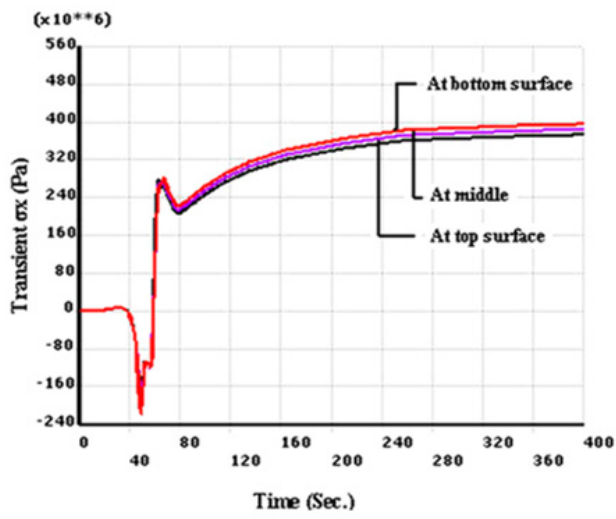

(b)

Figure 17. Transient longitudinal residual stress in moving cooling spot: (a) in Al-Mg alloy; (b) in Ti$6 \mathrm{Al}-4 \mathrm{~V}$ alloy 


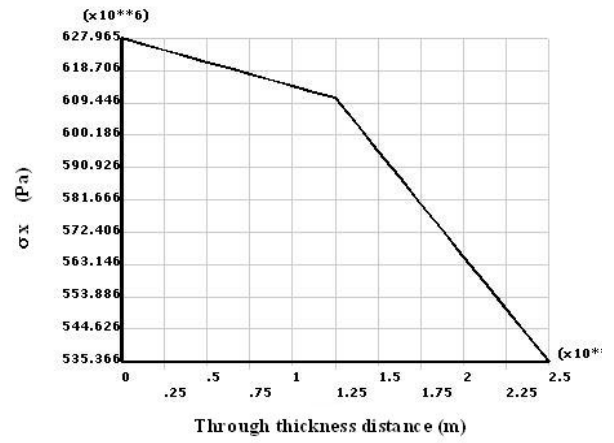

(a)

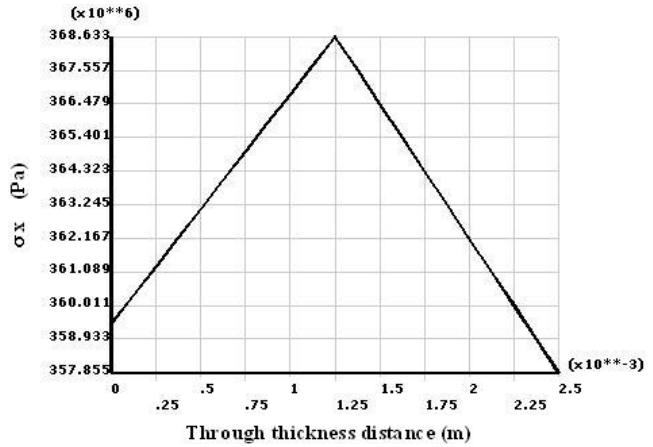

(b)

Figure 18. Final longitudinal Residual Stress through Thickness: (a) In Conventional Welding; (b) In Trailing Heat Sink.

\subsubsection{Longitudinal plastic strain behavior}

In welding process, the residual stress magnitude based on the inherent strain or plastic strain, so the analysis of strain behavior is important to characterize the minimization of residual stress. In the work done by (soul \& yan hua,2006) the transient longitudinal plastic strain profiles were analyzed at two nodes and presented in figure 19. In conventional welding the plastic strain at the centerline $(Y=0 \mathrm{~mm})$ seams to be higher than the point a little moved a way from the center line $(\mathrm{Y}=2.5 \mathrm{~mm})$. However; after including dynamic cooling spot figure 19b, significant change in plastic strain behavior was obtained. The plastic strain at the centerline became lower than that at $(2.5 \mathrm{~mm})$, it is clear that the overall plastic strain magnitude were minimized due to the used technique.

The minimization behavior refers to the complex tensioning effect based on the temperature topography. Moreover, due to the surrounding hot material, the temperature increased again behind the trailing cooling spot, and some of strains is released or partial annealing process occurs. In practical welding, it is difficult to obtain constant temperature through thickness with respect to the time whatever it is thin. This nonhomogeneity refers to the three heat transfer conditions which may occurs at the upper surface rather than at the lower surface, hence the temperature is still higher above. To characterize the change in plastic strain through the thickness, simulated result of $2.5 \mathrm{~mm}$ modeled welded titanium sheet is analyzed. However, when no backing used in welding, the cooling rate at upper surface is still more than at lower surface. Figure 20 reveals that the maximum plastic strain occurs at the upper surface but after trailing heat sink introduced figure $20 \mathrm{~b}$, all the plastic strain magnitude through the thickness became close to each other due to the process effects. 


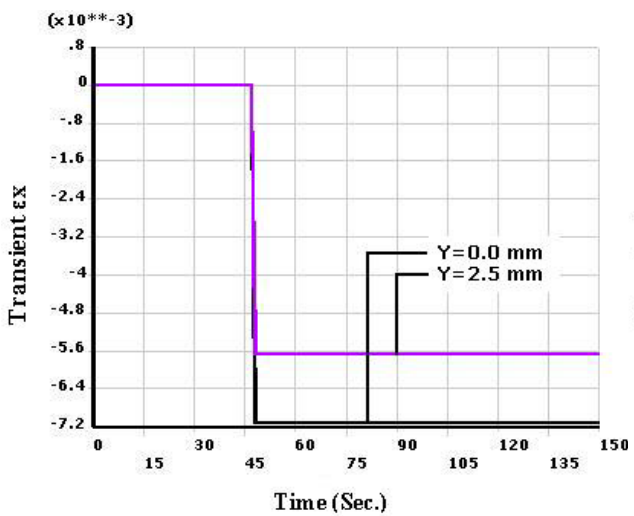

(a)

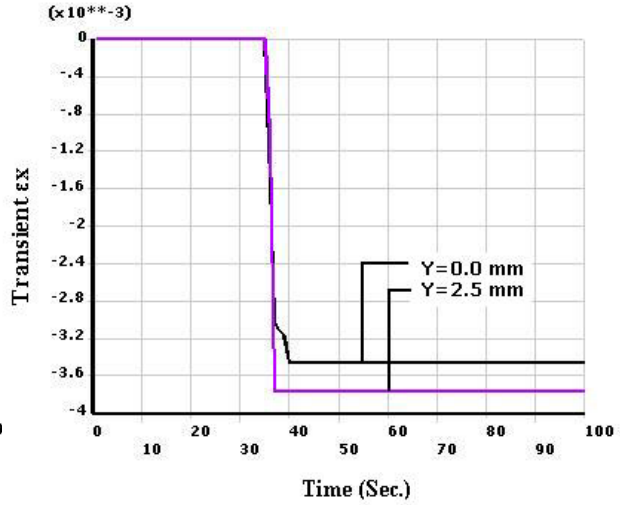

(b)

Figure 19. Transient plastic strain: (a) in conventional welding; (b) in trailing heat sink.

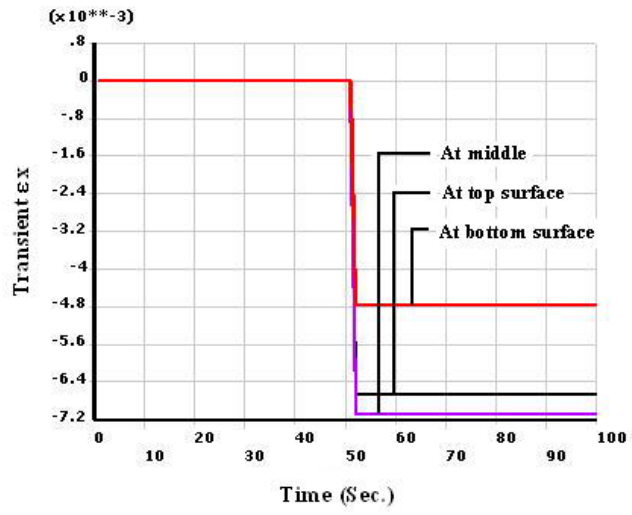

(a)

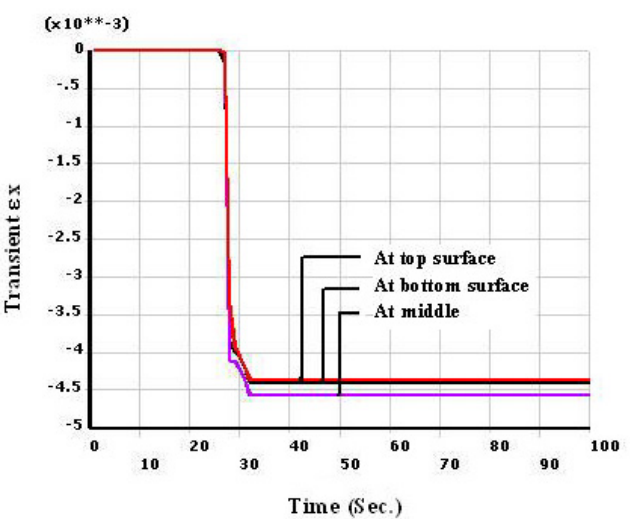

(b)

Figure 20. Plastic strain through depth: (a) in conventional welding; (b) in trailing heat sink.

Moreover, the plastic strain magnitude at the upper surface is less or equal the strain at the lower surface which cause a balance in strains around the neutral axis. Therefore, balancing of forces occurred, and bending distortion minimized or can be eliminate depends on the degree of balancing. It is conclude that the reduction in overall longitudinal plastic strain magnitude is the source of longitudinal residual stress minimization. This results can be coupled with that obtained in Figs. 15b and 17b. 


\subsubsection{Effectiveness of the process on longitudinal welded cylinder model}

In the cylindrical model the trailing heat sink considered to be moving behind the heat source at the bottom side. This consideration according to the results obtained in conventional welding which indicate that the maximum axial residual tensile stress occurred at inner the surface. The temperature distribution resulted from the thermal analysis of those conventional welding and that including trailing cooling spot welding process stated in the above sections are studied at welding time of 20s. Contour plots of the temperature distribution under the two conditions are shown in figure 21. Comparing the isotherms in both process results, the contours behind the heat source were shifted in the front of trailing cooling spot due to abnormal heat transfer process. The homogeneous heat transfer in conventional welding looses its stability after cooling spot was introduced. Moreover, the temperature magnitude in compressed contours was decreased due to the absorbed heat at high temperature behind the torch by the action of cooling. The effect of change in heat transfer mechanism on the distribution of axial residual stress can be seen in figure 22. the residual stress profile is completely different after introduced dynamic cooling spot. Because of the cylindrical shape is different from the flat from point of view the stiffness resistance from point of view, the reduction in final residual stress in cylindrical model is not sufficient when it is compared with the flat model which is still thicker.

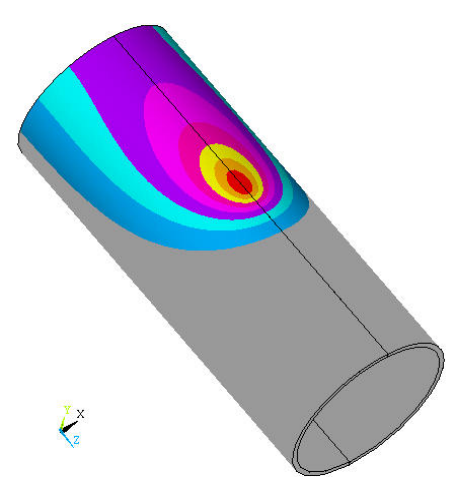

(a)
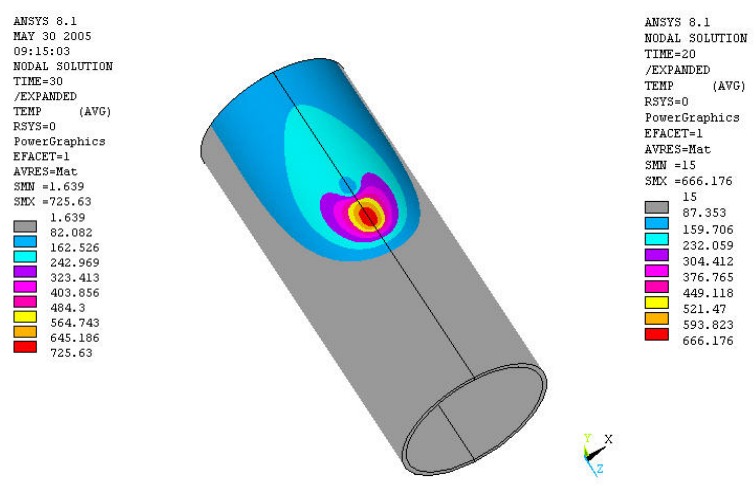

(b)

Figure 21. Temperature distribution at $20 \mathrm{~s}$ : (a) conventional welding; (b) trailing heat sink. 


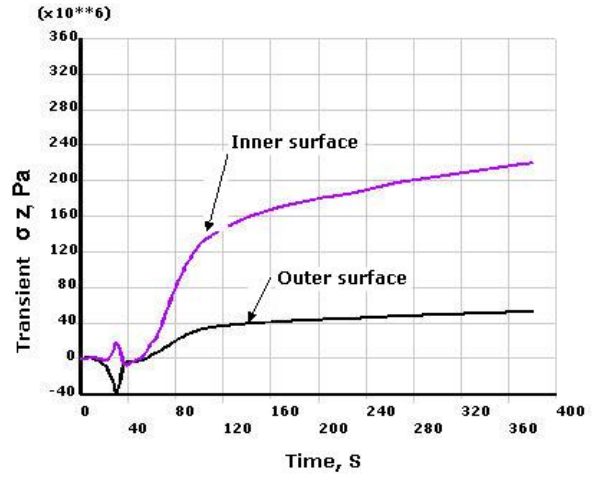

(a)

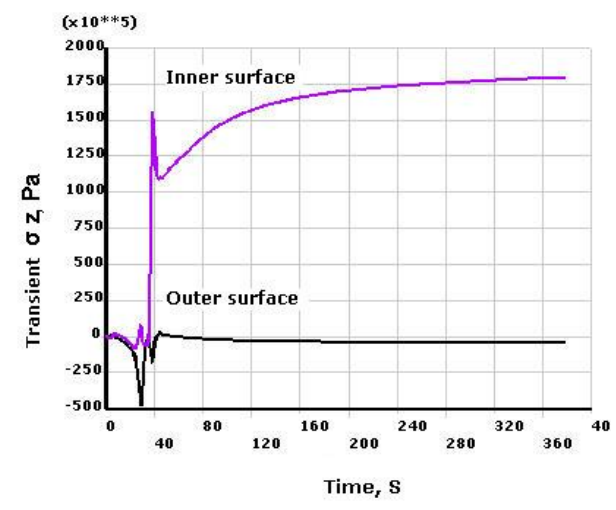

(b)

Figure 22. Transient axial residual stress (a) conventional welding; (b) trailing heat sink.

\subsubsection{Control of distortion by trailing cooling spot}

As discussed in the previous sections, how the mechanism of heat transfer was changed after introducing heat sink. Therefore, it results in thermal tension that differs from what occurs in conventional one. The degree of tension depends on the position of the cooling spot with respect to the heat source, or the proper parameters as denoted in ( $\mathrm{Li}$ et al, 2004, 2005; Soul et. al., 2006). All the above results show the minimization in longitudinal residual stress that refers to the decrease in responsible plastic strain. All of the previous parameters in addition of balancing stress and strain on the upper and under the neutral axis bring the elimination of the structure distortion as depicted in figure23 and figure 24.
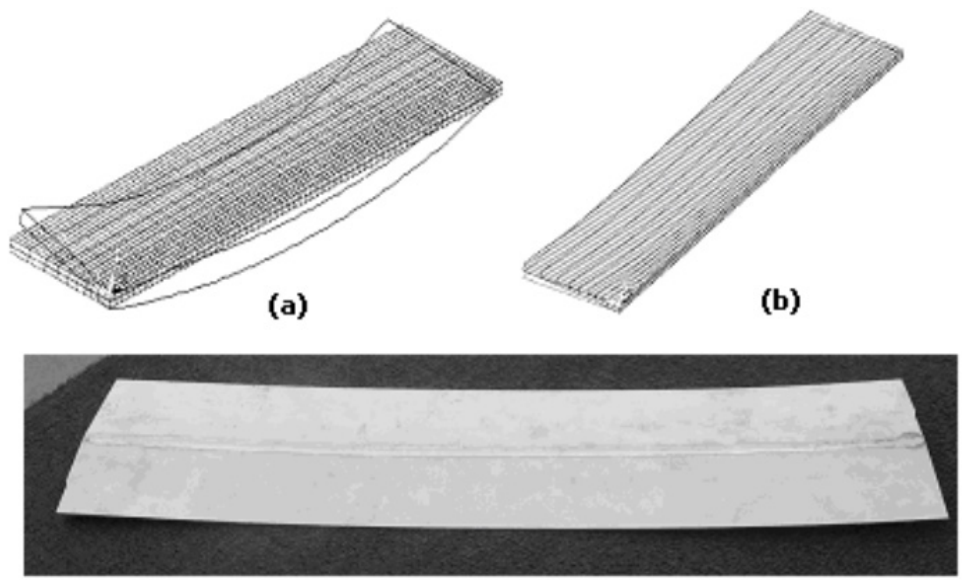

(c)

Figure 23. Final distortion: (a) conventional process; (b) with heat sink process; (c) welded experiment sample. 


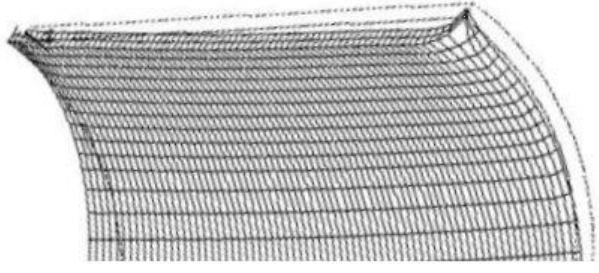

(a)

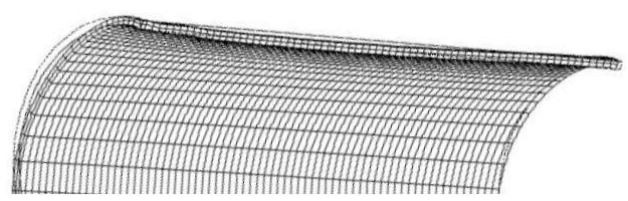

(b)

Figure 24. Final deformed model: (a) GTAW process; (b) DC-LSND process.

\subsection{Optimization of thermal tensioning in welded shell element}

There are many different methods of welding deformation and stress reduction. At the same time, the main principles are the same. Classification of the mitigation techniques helps to understand its performance capabilities and limitations. According to the basic mechanisms on which the techniques are based.

\subsubsection{Effect of the laser heating spot on the temperature distribution}

The Introducing of heating spot besides the welding reveals an increase in temperature at fusion zone and other near regions comparing with the conventional welding itself. So, to obtain the similar contours of temperature at welding line, the heat input from the torch were decreased about $19 \%$. Figure 25 shows the predicted temperature distribution in conventional welding and moving heating spots respectively. The selected separated positions for laser spots were $34 \mathrm{~mm}$ from the centerline. It is clear, that the heating spot not only affects the temperature distribution in the front of heat source, but also enlarges the contours in transverse direction far way from centerline. This is due to the increasing of the total energy input with respect to small specimen width. However the contours change completely at the position of spots due to the concentration of laser heating.
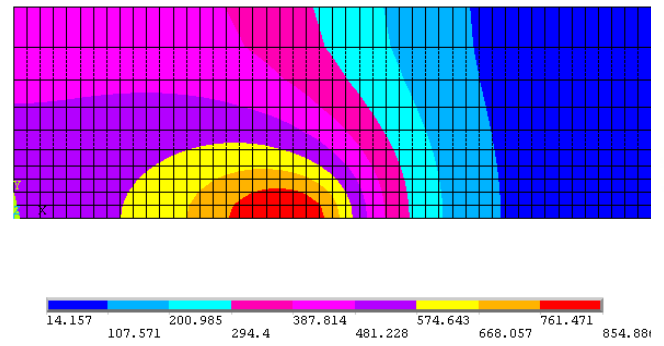

(a)
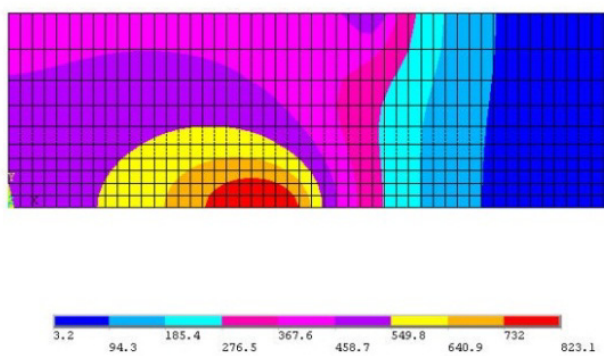

(b)

Figure 25. Temperature distribution contours: (a) conventional welding; (b) moving heat spot. 


\subsubsection{Effects of the laser heating spot on the stress and strain behavior}

Longitudinal residual stresses and plastic strains in transverse direction with respect to the time are presented in figure 26. The analyzed points are taken at different distance from the centerline in the mid length of the model. The distance of heat spot from weld centerline is $25 \mathrm{~mm}$. The tensile stress profile developed during cooling cycle show different behavior compared to the result obtained from the conventional welding figure 26a. However, the transient longitudinal residual stress stay constant during some period of time ( 40s), Thus, at that time the heat source already switched off. This behavior is related to the effect of spot heating. The heated material by laser spot were expanded to the direction of welding centerline, in the same time the metal behind the torch vastly contracted, now there are two possibilities, first, if the material is heated for enough distance in transfer direction the contraction of welded material don't meet the resistance from the heated material for mentioned period of time above, in the opposite of the conventional process were the cold material restrained the contraction. Second, when the material contacted at the welding line the heated material by spots expanded in the direction of welding line, hence the material may contracted without more tension due to the expanded material neighboring during the above mentioned period. Moreover the residual stress using this method still more than in cooling spot technique. Concerning the plastic strain behavior in this technique, the transient plastic strain result from laser heating spots reveals complicated profile too; the longitudinal plastic compressive strain is caused by the expansion of the heated material being constraint by the cooler material nearby.

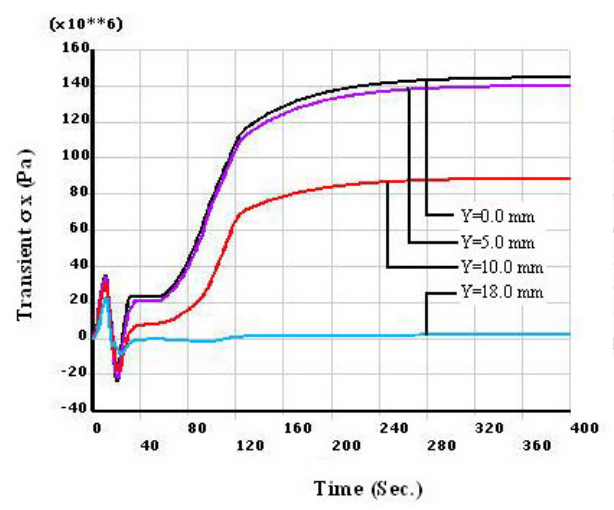

(a)

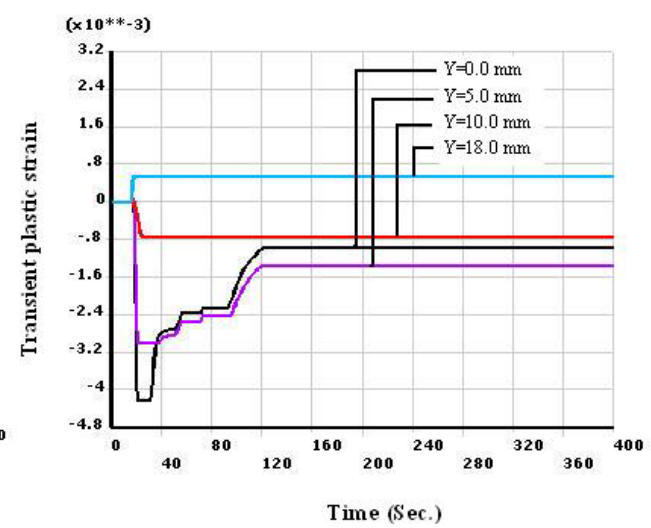

(a)

Figure 26. Simulated results in moving heating spots: (a) Transient residual stress; (b) Transient plastic strain

The rising of temperature far ways from zone induced by laser spots affects the material properties and decrease it is stiffness, hence the resistance of material to the weld metal contraction were reduced. Moreover the transient longitudinal plastic take long period of 
time to accomplished final magnitude due to increase of overall body temperature, and it's value less than from that obtained by trailing heat sink technique figure $17 \mathrm{a}$, but the residual stress and distortion is still more. This phenomenon may refer to other strains results in transverse and through thickness direction, which need more details for their behavior under this process due to the complicated strain interaction in the three dimensional

\subsubsection{Processes parameters controlling distortion degree}

It is clear from the previous studies that any modifications in the longitudinal residual stress results from temperature modification or heat transfer enhancement. As what happen in the simulated techniques, and the main control on the twin problem is how the temperature topography looks like. However, the change of processes parameters will give changes in temperature topography. Therefore, different temperature topography generate different tensioning process or different strain interaction. According to the previous explanation, for the process optimization investigation of the effect of the distance between the heating spot and weld centerline on the cambering distortion magnitude was carried out. Figure 27 presents the degree of distortion obtained from computational results at different distance of the laser spot. The results show that the distortion increases as the distance increases. However, after introducing the heat sink process as depicted in figure $27 \mathrm{~b}$, the distortion may disappear and the calculated displacement is only $1.3 \mathrm{~mm}$. The result is quite reasonable according to the minimized and balanced residual longitudinal stress and plastic strain or the balanced forces and moment which become insignificant to produce the curvature along welding line as mentioned in the previous sections. Moreover, the displacement in laser heating spot was reduced but still higher than that obtained in the cooling technique. At this point comparing both mitigation techniques, it can be concluded that at the same reduction of distortion, still the moving cooling spot more effective technique than thermal tensioning for residual stress minimization in thin element.

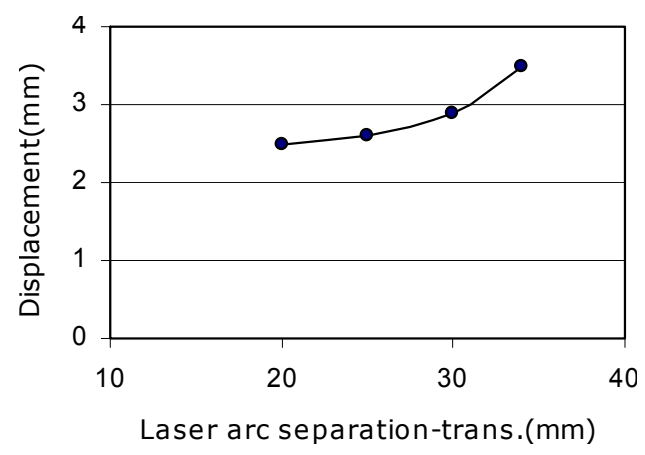

(a)

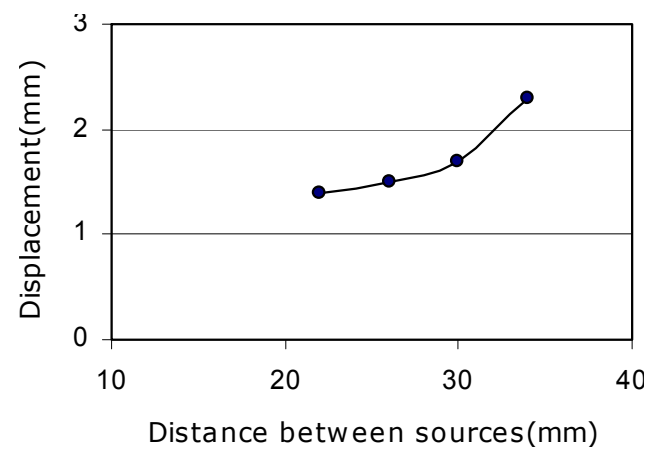

(b)

Figure 27. Parameters effects the processes performance: (a) heating spots; (b) cooling spot. 


\section{Conclusions}

One of the major problems induced during welding of thin element structure are the twin Problem. Residual stresses reduce the performance of welded component when they have the same sense with the working stress in service. Other disadvantage of residual stress is promoting the stress corrosion cracking. Distortion from other side, impairs the structure appearance and causes misalignment during assemblies. During the years, many mitigating techniques are developed in literature to reduce the residual stress and elimination of distortion. In the end of last century, techniques introduced thermal tensioning or temperature modification were creative, that including (LSND) and heating techniques. When the dynamic action of these techniques applied, they became more suitable to approximate the solution of the problem, because it is dealing with temperature modification, and it is known that the temperature is the source of the problem. In this chapter, the two mentioned active mitigating techniques were investigated in dynamic action and correlated with each other. The main fields of interest for the investigation are temperature fields, longitudinal residual stress and strain in addition to the bending distortion. Atomized cooling water with heat transfer coefficient were proposed, also laser heating spot beside the torch with proper heat input were considered. The output results of this investigation summarized as following:

- The change of heat transfer enhancement produce temperature modification or different temperature topography.

- The modification of temperature distribution generate different tensioning inside the body, therefore new abnormal strain interaction in different direction.

- Due to complexity stiffness based-response for different shape, the transient stress behavior developed in the bead on plate model show different profile correlate with that in the cylinder model.

- $\quad$ One of the major advantages of FE optimization approach over welding trials was that the models enabled the transient stresses and strains during welding to be considered. This greatly simplified the understanding and optimization process.

- During the DC-LSND process, the thermal history for metal in the weld centerline and at closed region passed more than one thermal cycles, as (heating-cooling-heatingcooling) and the duration time for staying the metal at high temperature is shorter than in conventional process. This is found to reveal different stress and strain history profiles at this region compared with the profiles obtained in the conventional process.

- The significant reduction in the residual stress obtained at the top of surface and the maximum stress at the middle of the thickness. This helps to balance the shrinkage forces above and under the weld metal center, and distortion can be prevented

- The suggested techniques gave a reduction of the peak residual stress. Optimization of both DC-LSND and thermal tensioning can give similar reduction or elimination of bending distortion of such used models thickness. At this optimization still the DCLSND method has a better effectiveness on longitudinal residual stress minimization

Future work analysis need for strains in other ( $Y$ and $Z)$ directions, to see it is behavior after applying the above techniques and correlate with the longitudinal direction. 


\section{Author details}

Farag Soul

University of Elmergeb, Faculty of Engineering, Libya

Hamdy Nada

University of Menoufia, Faculty of Engineering, Egypt

\section{References}

Withers P. J. \& Bhadeshia H. (2000), Residual Stress - II: Nature and Origins, Mat. Sci. Tech. Rudd C. O. (199), Residual stresses and their measurement, Proc. 1st Int. Conf. on Quenching $\mathcal{E}$ Control of Distortion, Chicago, Illinois, USA, 193-198.

Borland D. W.(1994), Residual stress measurement - Methods, limitations and significance, Proc. 2nd Australian Int. Conf. Surface Engineering, Adelaide, 114-121.

Kandil F. A. et. al. (2001); A Review Of Residual Stress Measurement Methods -A Guide To Technique Selection, NPL Report MATC(A)O4.

Brien E. O. (2000), Residual Stress - Friend and Foe: A Civil Aircraft Perspective, ICRS-6, Oxford, UK, 10-12 July, vol. 1, 13-21.

Evans E. B.(1986), "Residual stresses in processing." Encyclopaedia of Materials Science $\mathcal{E}$ Engineering, Vol. 6, 4183-4188

Littmann W. E.(1964), Measurement and significance of residual macrostress in steel”, SAE 793A, Proc. of the Automatic Eng. Cong., Detroit, MI, 13-17.

Airbus 2000, http://www.airbus.com /gmf99_1.html

Guan Q. (1999), A survey of development in welding stress and distortion controlling in aerospace manufacturing engineering in china Welding in the world, Pergamon press Ltd, 43(1).

Hansen B.(1968), Welding stresses and deformation. Svejse Copenhagen report no. 68.07 edition, 1968. in Danish.

Okerblom N. O. (1955), The Calculations Of Deformations Of Welded Metal Structures. Mashgiz, Moscow-Leningrad, 1955.

Puchaicela J. (1997), Control of distortion of welded steel structures, Welding J., pp.49-52.

Masubuchi K. (1980), Analysis of welded structures, Pergamon Press, London.

Radaj R. (1992), Heat Effects of Welding, Spring-Verlag.

Goldak J. et. al. (1992), Coupling heat transfer, microstructure evolution and thermal stress analysis in weld mechanics, Proc. of IUTAM Mechanical effects of welding, Springer Verlag, Berlin.

Lindgren L. (2001), Finite element modeling and simulation of welding part 1: Increased Complexity, Journal of thermal stress, Vol. 24, pp 141-192.

Lindgren L. (2001), Finite element modeling and simulation of welding part 2: Improved materials modeling, Journal of Thermal Stresses, Vol. 24, pp 195-231.

Lindgren L. (2001), Finite element modeling and simulation of welding part 3: Efficiency and Integration, Journal of thermal stress, Vol. 24, 2001, pp 305-334. 
Tall L. (1991), Residual Stresses In Welded Plates--A Theoretical Study, Weld. J., Vol 43 (No. 1), P 10s-23s

Hibbit H.D. \& Marcel P.V. (1972), A Numerical Thermomechanical Model For The Welding And Subsequent Loading of A Fabricated Structure, Nsrdc Contract No. N00014-67-A019-0006, Tech. Rep. No. 2, Department Of The Navy.

Muraki T. et. al. (1975), Analysis Of Thermal Stresses And Metal Movement During Welding-- Part I: Analytical Study; Part Ii: Comparison Of Experimental Data And Analytical Results, J. Eng. Mater. Technol. (Trans. Asme), 1975, P 81-84, 85-91

Rybicki E.F. et al. (1978), A Finite-Element Model For Residual Stresses And Deflection In Girth-Butt Welded Pipes, J. Pressure Vessel Technol. (Trans. Asme), Vol 100, P 256-262

Courant R. (1943), Variation Methods For The Solution Of Equilibrium And Vibration, Bulletin Of The American Mathematical Society, 49. Pp 1-23.

Dong P. et al. (1998), Residual Stress Analysis Of A Multi-Pass Girth Weld, Asme PrpFatigue, Fracture, And Residual Stresses, 373, Pp. 421-431.

Feng Z. et al. (1996), A Finite Element Model For Residual Stress In Repair Welds, Asme PvpResidual Stresses In Design, Fabrication, Assessment And Repair, 327, Pp. 119-125.

Karlsson L. et al. (1989), Residual Stresses And Deformatins In A Welded Thin-Walled Pipe, Asme Prp- Weld Residual Stress Andplastic Deformation, 173, Pp. 7-10.

Grong Q. \& Myhr O. R. (1993), Modelling Of The Strength Distribution In The Heat Affected Zone Of 6082-T6 Aluminum Weldments" Mathematical Modelling Of Weld Phenomena, The Institute Of Materials, London, Pp. 300-311.

Voss O. et. al. (1999), Consideration Of Microstructure Transformations In The Calculation Of Residual Stresses And Distortion Of Larger Weldments, Mathematical Modeling Of Weld Phenomena 4, The Institute Of Materials, Pp584-596.

Tenga T. L. \& Linb C. (1998), Effect Of Welding Conditions On Residual Stresses Due To Butt Welds, International Journal Of Pressure Vessels And Piping 75, 857-864.

Li J. et. al. (2004), Studies On Characteristics Of Temperature Field During Gtaw With A Trailing Heat Sink For Titanium Sheet, J. Of Mater. Proc.Tech. 147,328-335.

Karlsson R. I. \& Josefson B. L. (1990), Three-Dimensional Finite Element Analysis Of Temperatures And Stresses In A Single-Pass Butt-Welded Pipe, Asme-Journal Of Pressure Vessel Technology, 112, Pp. 76-84.

Junek L. et. al. (1999), Residual Stress Simulation Incorporating Weld HAZ Microstructure, Asme Prp- Fracture, Fatigue And Weld Residual Stress, 393, Pp. 179-192.

Vincent Y. et. al. (1999), On The Validation Of The Models Related To The Prevision Of The Haz Behavior, Asme Prp-Fracture, Fatigue And Weld Residual Stress, 393, Pp. 193-200.

Dubois D. et. al. (1984), Numerical Simulation Of A Welding Operation: Calculation Of Residual Stresses And Hydrogen Diffusion, Asme Fifth International Conference On Pressure Vessel Technology, Materials And Manufacturing, Ii, San Francisco, Ca, Pp. 1210 1238

Gatovskii K. M. (1980) \& Karkhin V. A. (1980), Theory Of Welding Stresses And Deformations, Leningrad Shipbuilding Institute, Rus. 
Withers P. J. \& Bhadeshia H. K. (20000), Residual Stress, Measurement Techniques, Mat. Sci. Tech., 2000.

Borland D. W. (1994), Residual Stress Measurement Methods, Limitations And Significance, Proc. 2nd Australian Int. Conf. Surface Engineering, Adelaide, March 1994, 114-121.

Noyan I. C. , Defining Residual Stresses In Thin Film Structures", Advances In X-Ray Analysis, Vol.35, 461-473.

Guan Q. et al. (1986), Transient Welding Strain Measurement By Moire Technique. Transactions Of Chinese Welding Society, 7(1)

Artem P.(2001). Ph.D thesis, computer simulation of residual stress and distortion of thick plates in multi-electrode submerged arc welding.

Soul F. \& Yanhua Z.(2005), Numerical Study Of Residual Stress Field During Arc Welding With Trailing Heat Sink. Fluid Structure Interaction And Moving Boundary Problem, Transaction Engineering Science,Vol.84,683-692, Witpress.

Soul F. \& Yanhua Z. (2005), Thermo-Mechanical Analysis of Longitudinal Welded Aluminum Alloy Cylinder Using 3D FEM, The Fifth International Forum on Aluminum Ships, Tokyo.

Huang T. D. et. al. (2004), Fabrication And Engineering Technology For Lightweight Ship Structures, Part 1: Distortions And Residual Stresses In Panel Fabrication, Journal of Ship Production, 20(1), P.43-59,

Andersen L. F. (2000), Residual Stress And Deformations In Steel Structures - PhD, Technical University Of Denmark, Department Of Naval Architecture And Offshore Engineering.

Conrady C. \& Dull R. (1995), Prediction Techniques For Distortion Control, Report-Edison Welding Institute.

Michaleris P. et al. (1999), Minimization Of Welding Residual Stress And Distortion In Large Structures. Welding Journal, Welding Research Supplement, 361-366.

Michaleris P. \& Sun X. (1997), Finite Element Analysis Of Thermal Tensioning Techniques Mitigating Weld Buckling Distortion. Welding Journal,Vol.76, 451-457.

Conrardy C. \& Dull R. (1997), Control Of Distortion In Thin Ship Panels. Journal Of Ship Production, Vol.13, 83-92.

Guan Q. et a (1994) . Low Stress No-Distortion (Lsnd)Welding A New Technique For Thin Materials. Iiw Doc. X-1190-89, Welding In The World, Vol.33.

Guan Q. et al. (1993), Dynamically Controlled Low Stress No-Distortion Technology And Its Apparatus. Chinese Patent 9310690.8.

Guan Q. et al. (1996), Low Stress No Distortion Welding For Aerospace Structures. China Welding, Vol.5,1-9.

Li J. et al (2004). Stress And Distortion Mitigation Technique For Welding Titanium Alloy Thin Sheet. Sci.Technol. Weld. Join., Vol.9(5),451-45

Soul F. \& Yanhua Z. (2006), Numerical Study On Stress Induced Cambering Distortion And Its Mitigation In Welded Titanium Alloy Sheet. J. Sci. Technol. Weld. Join., Uk, Vol.11, 688- 693. 
Soul1 F. et. al. (2010), Residual Stress Correlation In Two Different Mitigation Techniques Using FEA, Advanced Materials Research Vols. 83-86 (2010) Pp 1254-1261

Pavelic V. et al. (1969), Experimental And Computed Temperature Histories In Gas Tungsten Arc Welding, Welding Journal Research Supplement, 48, 295s-305s.

Goldak J. et. al. (1984), A New Finite Element Model For Welding Heat Sources, Metallurgical Transactions B, Vol. 15b, 1984, P 229-305.

E.M. van der $\mathrm{Aa}$ (2007), PhD thesis, Delft University of Technology 